\title{
The double-ratio method (DRM): a robust three-probe sap flow technology that can accurately measure high, low and reverse flows
}

\author{
Zijuan Deng ${ }^{1}$, Heather Vice ${ }^{2}$, Matthew Gilbert ${ }^{3}$, Mark Adams $^{4}$, and Thomas Buckley ${ }^{2}$ \\ ${ }^{1}$ Flinders University of South Australia \\ ${ }^{2}$ University of California Davis \\ ${ }^{3} \mathrm{UC}$ Davis \\ ${ }^{4}$ Swinburne University of Technology
}

September 16, 2020

\begin{abstract}
Sap velocity measurements are useful in fields ranging from plant water relations to hydrology at a range of scales. Heat-pulse based techniques are among the most common methods to measure sap velocity, but most lack the ability to measure velocities across a wide range, including very high, very low and negative velocities (reverse flow). We propose a new method, the doubleratio method (DRM), which is robust across an unprecedented range of sap velocities and can provide real-time estimates of the thermal diffusivity of wood. The DRM employs one temperature sensor proximal and two distal to the heat pulse probe and facilitates several theoretical, heat-based approaches to quantifying sap velocity. We tested the DRM using whole-tree lysimetry in Eucalyptus cypellocarpa and found strong agreement across a wide range of velocities.

Zijuan Deng ${ }^{1 *}$

Heather Vice ${ }^{3}$

Matthew E Gilbert ${ }^{3}$

Mark A Adams ${ }^{2}$

Thomas N Buckley ${ }^{3 *}$

${ }^{1}$ Centre for Carbon, Water and Food, the University of Sydney; Current: College of Science and Engineering, Flinders University, Australia

${ }^{2}$ School of Science, Faculty of Science, Engineering \& Technology, Swinburne University of Technology, Australia

${ }^{3}$ Department of Plant Sciences, University of California, Davis, CA, United States

*Corresponding authors:

Zijuan Deng

zijuan.deng@flinders.edu.au/rosedeng0810@gmail.com

*These authors contributed equally to this work.

Abstract
\end{abstract}


Sap velocity measurements are useful in fields ranging from plant water relations to hydrology at a range of scales. Heat-pulse based techniques are among the most common methods to measure sap velocity, but most lack the ability to measure velocities across a wide range, including very high, very low and negative velocities (reverse flow). We propose a new method, the double-ratio method (DRM), which is robust across an unprecedented range of sap velocities and can provide real-time estimates of the thermal diffusivity of wood. The DRM employs one temperature sensor proximal and two distal to the heat pulse probe and facilitates several theoretical, heat-based approaches to quantifying sap velocity. We tested the DRM using whole-tree lysimetry inEucalyptus cypellocarpa and found strong agreement across a wide range of velocities.

Keywords:

Sap flow, sap flux, sap velocity, heat-pulse based technique,Eucalyptus cypellocarpa , thermal diffusivity, double-ratio method

\section{Introduction}

Sap velocity measurements using heat-tracing techniques have been important means for studying plant water relations from whole-plant to catchment scale in the tree physiology, forestry and hydrology communities (Thomas N. Buckley, Turnbull, Pfautsch, \& Adams, 2011; Thomas N Buckley, Turnbull, Pfautsch, Gharun, \& Adams, 2012; Cermak, Kucera, Bauerle, Phillips, \& Hinckley, 2007; Steppe, Vandegehuchte, Tognetti, \& Mencuccini, 2015; Wilson, Hanson, Mulholland, Baldocchi, \& Wullschleger, 2001). There are many heat-dissipation-based methods, but all have one or more weaknesses. Constant-power or Granier style probes (Granier, 1985) are inexpensive and robust but require empirical calibration (Clearwater, Meinzer, Andrade, Goldstein, \& Holbrook, 1999), consume large amounts of electrical power and cannot accurately measure small or negative sap velocities. Heat-pulse based methods such as the Tmax method (Cohen, Fuchs, \& Green, 1981), compensation heat pulse method (CHPM) (SR Green \& Clothier, 1988), heat field deformation method (HFD) (Nadezhdina, Cermak, \& Nadezhdin, 1998), heat ratio method (HRM) (Burgess et al., 2001), and Sapflow + method (Vandegehuchte \& Steppe, 2012c) use little power and are traceable to first principles, but also have critical limitations. Tmax, CHPM and HFD cannot measure low or negative velocities (Steve Green, Clothier, \& Jardine, 2003; Vandegehuchte \& Steppe, 2012c); Sapflow + suffers from difficulty in model identification; and the HRM fails at high sap velocities (Bleby, McElrone, \& Burgess, 2008; Flo, Martinez-Vilalta, Steppe, Schuldt, \& Poyatos, 2019; Pearsall, Williams, Castorani, Bleby, \& McElrone, 2014).

In most heat pulse-based methods, sapwood thermal diffusivity, $k$, is a crucial parameter in calculation of the sap velocity (López-Bernal, Alcántara, \& Villalobos, 2014; Vandegehuchte \& Steppe, 2012a). An arbitrary value of $k$ is usually set or obtained from empirical function related to sapwood moisture content $(m c)$ (Burgess et al., 2001; Marshall, 1958; Vandegehuchte \& Steppe, 2012a). Howeverk is seemingly not constant, and can change over seasons (Burgess et al., 2001; Chen, Miller, Rubin, \& Baldocchi, 2012) or even diurnally (López-Bernal et al., 2014), with uncertain consequences for the accuracy of calculated sap velocity. Velocity estimates from the Tmax method depend only on $k$ and known parameters. Therefore if sap velocity is known to be zero, such as at night time after prolonged wet conditions, $k$ can be directly inferred and then treated as a constant until such a time that it can be re-measured (Burgess et al., 2001). Inverse modelling has also been used to calibrate $k$ (Chen et al., 2012; Vandegehuchte \& Steppe, 2012a), notwithstanding measurement uncertainties and issues with probe alignment. For example, empirical functions to infer $k$ from sapwood properties and $m c$ could be validated at low sap velocities under $20 \mathrm{~cm} \mathrm{~h}^{-1}$ (Vandegehuchte \& Steppe, 2012b), however, such procedures require knowledge of $m c$, which may vary diurnally (López-Bernal et al., 2014). $k$ has never been estimated in vivo, in real time, at higher sap velocities.

Pearsall et al. (2014) proposed a method for extending the range of sap velocities that can be reliably measured using heat pulse approaches. They combined the HRM and CHPM, using the HRM to detect small and negative sap velocities and the CHPM to detect high sap velocities. One limitation of that approach is the lack of a non-arbitrary method to selecting whether to use the HRM- or CHPM-derived estimate of sap velocity at any given time. Another concern is that this approach alternates between two very different 
measurement approaches: an average over time of sap velocity estimated from the ratio of temperature rises in two sensors (HRM), or an inference based on estimation of the single instant at which two temperature rises are equal (CHPM). Thus, research communities that rely on sap velocity measurements lack a single method that is at once energy-efficient, objective, robust and capable of measuring negative, low and high sap velocities with a single measurement principle.

We developed a new and efficient algorithm, the double-ratio method (DRM), that combines many of the strengths of existing methods and is robust across an unprecedented range of sap velocities, from moderate negative velocities to very large positive velocities. The DRM is an extension of the HRM in which an additional temperature sensor (Probe \#3) is installed distal to both temperature sensors used in the HRM. The DRM estimates sap velocity based on the same principles as the HRM - namely, by calculating the ratios of heat pulse-induced temperature rises measured in different probes. Two different velocity estimates are produced - one based on Probe \#2 and \#1 and another based on Probe \#3 and \#2 - and the value with the lesser intrinsic uncertainty (which is calculated based on temperature rises and probe positions) is retained. Furthermore, the presence of a third sensor also enables CHPM estimates of flow, which can be combined with DRM-based estimates to allow real time estimation of $k$ under high-velocity conditions. We tested the DRM experimentally using weighing lysimeters and examined its capability by numerical modelling. We discuss the strengths and weaknesses of the DRM in relation to other commonly used heat-pulse based techniques.

2 Materials and Methods

\subsection{Theory}

\subsubsection{Background: heat pulse theory and the HRM}

Marshall (1958) showed that an instantaneous heat pulse at time $t=0$ causes an increase in temperature $\left(\delta_{\mathrm{i}}\right)$ at both axial $\left(x_{\mathrm{i}}\right)$ and azimuthal $\left(y_{\mathrm{i}}\right)$ positions relative to the heater at timet $(\mathrm{s})$, with negative and positive $x$ ivalues indicating positions proximal and distal to the heater, respectively:

$$
\delta_{i}=\frac{Q}{4 \pi \rho c k t} \exp \left(-\frac{\left(x_{i}-V t\right)^{2}+y_{i}^{2}}{4 k t}\right)
$$

where $V$ is the axial flux of sap (the sap flow $\left[\mathrm{m}^{3}{ }_{\text {sap }} \mathrm{s}^{-1}\right]$ per unit of cross sectional area of sapwood $\left[\mathrm{m}^{-2}\right.$ sapwood $] ; V$ thus has units of $\mathrm{m}^{3}{ }_{\text {sap }} \mathrm{m}^{-2}$ sapwood $\mathrm{s}^{-1}$, which is commonly expressed with the units centimetres per hour $\left.\left(\mathrm{cm} \mathrm{h}^{-1}\right)\right), Q$ is the total heat released per unit length of the heater $\left(\mathrm{J} \mathrm{m}^{-1}\right), \rho$ is the sapwood bulk density (including water and wood) $\left(\mathrm{kg} \mathrm{m}^{-3}\right), c$ is the sapwood heat capacity $\left(\mathrm{J} \mathrm{kg}^{-1} \mathrm{~K}^{-1}\right)$ and $k$ is the thermal diffusivity of the sapwood-water matrix $\left(\mathrm{m}^{2} \mathrm{~s}^{-1}\right)$. To avoid confusion arising from the historical use of the symbol " $V$ " to describe sap flux, we will follow previous authors in referring to $V$ as "sap velocity" (Edwards, Becker, \& Ėermák, 1996). Applying Eqn. 1 to two probe locations, $i$ and $j$, and rearranging provides an estimate of $V$ :

$$
V_{\mathrm{ij}}=\frac{2 k}{x_{j}-x_{i}} \ln \left(\frac{\delta_{j}}{\delta_{i}}\right)+\frac{x_{i}+x_{j}}{2 t}-\frac{y_{i}^{2}-y_{j}^{2}}{2 t\left(x_{j}-x_{i}\right)}
$$

In Eqn. 2, sap velocity is estimated from four types of quantities: a ratio of temperature increases between two probes $\left(\delta_{\mathrm{j}} / \delta_{\mathrm{i}}\right)$, the thermal diffusivity $k$, the positions of the two probes $\left(x_{\mathrm{i}}, x_{\mathrm{j}}, y_{\mathrm{i}}, y_{\mathrm{j}}\right)$, and the time elapsed since the heat pulse length $(t)$. If the two probes are parallel to one another (i.e., at identical azimuthal positions relative to the flow axis), then $y_{\mathrm{i}}=y_{\mathrm{j}}$, giving

$$
V_{\mathrm{ij}}=\frac{2 k}{x_{j}-x_{i}} \ln \left(\frac{\delta_{j}}{\delta_{i}}\right)+\frac{x_{i}+x_{j}}{2 t}
$$


In the HRM, Eqn. 3 is applied to two probes equidistant from the heater, one proximal (Probe \#1, $i=1$ ) and one distal $(\# 2, j=2)$, so that $x_{1}=-x_{2}$ (where $\left.x_{2}>0\right)$, giving

$$
V_{\mathrm{HRM}}=V_{12}=\frac{2 k}{x_{2}-x_{1}} \ln \left(\frac{\delta_{2}}{\delta_{1}}\right)
$$

A key strength of the HRM is that it can distinguish both small sap velocities and negative velocities (when sap flows in reverse, i.e., in a proximal direction, sap transfers heat towards Probe $\# 1$, causing $\delta_{1}>\delta_{2}$ and hence $\left.V_{12}<0\right)$.

\subsubsection{Problems with high sap velocities in the HRM}

In practice, Eqn. 4 is applied using experimental estimates of $\delta_{1}$ and $\delta_{2}\left(\hat{\delta}_{1}\right.$ and $\hat{\delta}_{2}$, respectively) that include measurement noise (error terms $\epsilon_{1}$ and $\epsilon_{2}$, respectively). Adding temperature noise terms to Eqn. 4 gives

$$
\hat{V}_{12}=\frac{2 k}{x_{2}-x_{1}} \ln \left(\frac{\hat{\delta}_{2}}{\hat{\delta}_{1}}\right)=\frac{2 k}{x_{2}-x_{1}} \ln \left(\frac{\delta_{2}+\varepsilon_{2}}{\delta_{1}+\varepsilon_{1}}\right) .
$$

$\epsilon_{1}$ and $\epsilon_{2}$ can be either positive or negative, since they are presumably random and symmetrically distributed around zero. When $V_{12}$ is large, $\delta_{1}$ is small (cf. Eqn. 1), and as a result the error term $\epsilon_{1}$ becomes large relative to $\delta_{1}$. If $\delta_{1}$ is small enough, $\delta_{1}+\epsilon_{1}$ will be negative for some measurements (i.e., $\epsilon_{1}$ will be negative and larger in magnitude than $\delta_{1}$ ). Moreover, the proportion of such measurements will increase as $\delta_{1}$ decreases, and hence as sap velocity increases. Any algorithm to apply Eqn. 4 must disregard such measurements, because they make the operand of the logarithm negative and thus undefined. But because $\epsilon_{1}$ is negative for the discarded points, the remaining (undiscarded) estimates of $\delta_{1}$ are positively biased, and hence the resulting estimates of $V_{12}$ are negatively biased. This bias increases as the true sap velocity increases, which manifests experimentally as a "plateau" or "ceiling" in inferred sap velocity (e.g. Fig. 1), often in the vicinity of 30-50 $\mathrm{cm} \mathrm{h}^{-1}$ (Flo et al., 2019; Pearsall et al., 2014; Pfautsch et al., 2011). Even if $\delta$ ${ }_{1}$ is non-negative, noise in $\delta_{1}$ at high velocities leads to the denominator of the heat ratio approaching zero, with the consequence that resulting estimates of $V_{12}$ can fluctuate by orders of magnitude.

[Insert Fig. 1 here]

\subsubsection{Principles of the Double-Ratio Method (DRM)}

To alleviate the negative bias of the HRM at high $V$, we propose a new method, the DRM, that uses a three-step approach to estimate $V$. First, $V_{12}$ is estimated as in the HRM. Second, an additional estimate of sap velocity ( $V_{23}$, Eqn. 6 ) is computed using the temperature rises at Probe \#2 and \#3, where Probe \#3 is located distal to Probe \#2 at the same distance as Probe \#2 is from Probe \#1 (so $x_{3}=3 \cdot x_{2}$ ):

$$
V_{23}=\frac{2 k}{x_{3}-x_{2}} \ln \left(\frac{\delta_{3}}{\delta_{2}}\right)+\frac{x_{2}+x_{3}}{2 t} .
$$

The third step is to choose between the two estimates of sap velocity ( $V_{12}$ and $\left.V_{23}\right)$ to give a single, final estimate of $V(V$ DRM $)$. On the grounds that measurements with less uncertainty are intrinsically preferable to those with greater uncertainty, we chose $V$ DRM as the value with the smaller measurement uncertainty $\left(\sigma_{12}\right.$ or $\left.\sigma_{23}\right)$ :

$V_{\mathrm{DRM}}=\left\{\begin{array}{l}V_{12} \\ V_{23}\end{array}\right.$ if $\begin{array}{c}\sigma_{12} \leq \sigma_{23} \\ \text { else }\end{array}$,

where $\sigma_{12}$ and $\sigma_{23}$ depend on the standard deviation of random noise for temperature sensors $\left(\sigma_{\mathrm{T}}\right)$ and 
on the estimated temperature rises at each probe $\left(\delta_{1}, \delta_{2}\right.$ and $\left.\delta_{3}\right)$, as follows:

$\sigma_{12}=\frac{2 k \sigma_{T}}{x_{2}-x_{1}} \sqrt{\frac{1}{\delta_{2}^{2}}+\frac{1}{\delta_{1}^{2}}}$, and
() $\sigma_{23}=\frac{2 k \sigma_{T}}{x_{3}-x_{2}} \sqrt{\frac{1}{\delta_{3}^{2}}+\frac{1}{\delta_{2}^{2}}}$.

When the true sap velocity is negative or very low, the uncertainty in $V_{23}$ will be greater than that for $V{ }_{12}$ and $V$ DRM will equal $V_{12}$, whereas at high velocities, $\sigma_{12}>\sigma_{23}$ and $V$ DRM will equal $V_{23}$. This selection procedure avoids the need to specify an arbitrary value of sap velocity at which to switch from one estimate to the other, as is required in the approach of Pearsall et al. (2014).

\subsubsection{Identifying the optimal time window for averaging sap velocity estimates}

In the HRM, $V_{12}$ is computed as the average of repeated instantaneous estimates during a fixed period after the heat pulse. ICT International suggests a $40 \mathrm{~s}$ time window, beginning $60 \mathrm{~s}$ after the pulse and ending at $100 \mathrm{~s}$. The uncertainty-based approach of the DRM provides an objective way to identify the optimal time window: namely, by choosing the period that minimizes intrinsic uncertainty in sap velocity, computed as the standard error of the mean estimated velocity (based on the theoretical uncertainty in $V$ DRM, not the standard deviation of a sample of instantaneous estimates):

$$
S E_{\mathrm{DRM}}=\frac{1}{n_{t}} \sqrt{\sum_{t=a}^{b} \sigma_{\mathrm{DRM}}^{2}(t)}
$$

where $n_{\mathrm{t}}$ is the number of time steps in the averaging window and $\sigma_{\mathrm{DRM}}$ is the lesser of $\sigma_{12}$ and $\sigma_{23}$ at each point in time. An efficient algorithm to minimize $\mathrm{SE}_{\mathrm{DRM}}$ is to locate the moment of minimum $\sigma$ DRM, compute the $\mathrm{SE}_{\mathrm{DRM}}$ for time windows of varying width around the moment and choose the width that gives the smallest $\mathrm{SE}_{\mathrm{DRM}}$. We tested a variety of values for $n_{\mathrm{t}}$.

Note that all equations were derived from Marshall's (1958) model (Eqn.1 ) under the assumption of an instantaneous heat pulse, whereas in reality the heat pulse occurs has a finite pulse length oft 0 . We corrected for this by shifting each temperature timecourse by $-t_{0} / 2$ before applying Eqn. $\mathbf{1}$. The effect of this treatment is shown in Supporting Information (SI) Notes S1 and Fig. S1 .

\subsection{Theoretical test of the DRM, HRM, CHPM and Tmax methods}

\subsubsection{Comparison of heat-pulse based methods}

To assess the theoretical viability of the DRM in comparison to other heat pulse methods, and to help optimize operational considerations such as the size and timing of averaging window(s), we used Eqn. 1to simulate timecourses of temperature following a heat pulse. We compared the predicted values of $V$ DRM (Eqn.7 ) with $V$ HRM (Eqn. 4 ), and also with two other estimates of $V$, based, respectively, on the CHPM (SR Green \& Clothier, 1988) and the Tmax method (Cohen et al., 1981) as modified by Kluitenberg and Ham (2004). In the CHPM, sap velocity is calculated at the time point $\left(t_{\mathrm{C}(1,3)}\right)$ when the temperature rises for Probe \#1 and \#3 are equal, so that the ratio of temperature rises is unity and the logarithmic term in Eqn. 4disappears, giving sap velocity as

$$
V_{\mathrm{CHPM}}=\frac{x_{1}+x_{3}}{2 t_{C(1,3)}}
$$

In the Tmax method, sap velocity is calculated from the time point at which the measured temperature rise is greatest after a given heat pulse $\left(t_{\mathrm{m}}\right)$. This leads to 


$$
V_{\operatorname{Tmax}}=\sqrt{\frac{4 k}{t_{0}} \ln \left(1-\frac{t_{0}}{t_{m}}\right)+\frac{x_{i}^{2}}{t_{m}\left(t_{m}-t_{0}\right)}},
$$

where $x_{i}$ is the distance of the probe $i$ from the heater (Probe \#2 is typically used because it usually has the greatest peak temperature). Note that if the true sap velocity is known to be zero, Eqn. $\mathbf{1 2}$ can be set equal to zero and rearranged to provide an estimate of $k$ :

$$
k=\frac{x_{i}^{2}}{4 t_{m}} \frac{t_{0}}{t_{m}-t_{0}}\left(\ln \frac{t_{0}}{t_{m}-t_{0}}\right)^{-1} .
$$

\section{Simulations}

We performed two sets of simulations. In the first set, we simulated timecourses of temperature rises for all three probes following a heat pulse, for sap velocity ranging from -10 to $80 \mathrm{~cm} \mathrm{~h}^{-1}$. We added Gaussian noise with a standard deviation of $0.02 \mathrm{~K}$ (using simulation module randn in MATLAB) to each timecourse. The code and procedures for generating the synthetic data in each timecourse and estimated sap velocity by each of the methods listed above are provided in the SI: Methods S1. Each such simulation was repeated $10^{3}$ times to estimate the probability distribution of each estimate of sap flux under random temperature noise. All simulations used sapwood properties given in TableS1 .

In the second set of simulations (Methods $\mathbf{S 2}$ ), we determined the sensitivity of each method to inaccuracy in $k$. Although heat pulse methods typically assume constant $k$, in practice it varies with $m c$, which may vary diurnally or seasonally in relation to changes in water potential and cycles of discharge and recharge of trunk water stores (Chen et al., 2012; López-Bernal et al., 2014). We simulated timecourses of temperature rises as for the first set of simulations for sap velocities between -10 to $80 \mathrm{~cm} \mathrm{~h}^{-1}$, while assuming each of three $m c=0.5,1.0,1.5 \mathrm{~g} \mathrm{~g}^{-1}$. We calculated $k$ from $m c$ for a basic density $\left(\rho_{\mathrm{b}}\right)$ of $0.5 \cdot 10^{3} \mathrm{~kg} \mathrm{~m}^{-3}$ using the relationship given by Vandegehuchte \& Steppe (2012b) (see Fig.S2 ).

\subsubsection{Theoretical test of internal calibration of $\mathrm{k}$}

Because $k$ may vary in relation to fluctuations in $m c$, using a constant value of $k$ in the DRM (or HRM) may cause systematic errors. To reduce such errors, $k$ can be estimatedin vivo by combining the sap velocity estimate from the DRM with an independent estimate of $V$, obtained from the CHPM, which does not explicitly depend on $k$. Although the CHPM itself has limitations (see Introduction), this procedure provides useful information about the magnitude of diurnal and seasonal changes in $k$. Setting $V$ DRM equal to $V$ CHPM under conditions of high sap velocity (so that $V_{\mathrm{DRM}}=V_{23}$ ) and solving for $k$ gives

$$
k=\frac{\left(x_{3}-x_{2}\right)\left(x_{1}-x_{2}\right)}{4 t_{C(1,3)} \ln \left(\frac{\delta_{3}}{\delta_{2}}\right)},
$$

where the temperature rises $\delta_{2}$ and $\delta_{3}$ are those measured at timet ${ }_{\mathrm{C}(1,3)}$. The smallest sap velocity at which Eqn.14 applies depends on the probe spacing and recording time, which limit the range of sap velocities that can be measured using the CHPM (Eqn. 11). For example, for our recording time (400 s after the heat pulse) and probe spacing (1.5 cm between Probe \#1 and \#3), the lowest sap velocity that could be inferred from Eqn.11 would correspond with the temperature rises of Probe \#1 and \#3 crossing over $400 \mathrm{~s}$ after the heat pulse, giving $V=\left(\begin{array}{ll}x_{1} & +x_{3}\end{array}\right) / 2 t=(-0.75+2.25) /(2[?] 400)=1.88[?] 10^{-3} \mathrm{~cm} \mathrm{~s}^{-1}$, or $6.75 \mathrm{~cm} \mathrm{~h}^{-1}$. The maximum $V$ at which Eqn. 14 applies depends on the $\sigma_{\mathrm{T}}, Q$ and $m c$. Fig. 2 illustrates how the maximum discernible sap velocity varies with $m c$ for various settings of probe and heat parameters (Table S1 ). The drier the sapwood, the broader the range of velocities to which Eqn.14 applies because smaller $m c$ leads to larger $k$.

We estimate $k$ as follows. First, we use Eqn. 13 to estimate $k$ prior to dawn, when sap velocity can be 
assumed to be zero. We apply that value of $k$ until $V$ rises high enough (e.g. $>6.75 \mathrm{~cm} \mathrm{~h}^{-1}$ ) in the early mornings for us to calculate $k$ from Eqn. 14. When $V$ exceeds the range in which Eqn. 14 is applicable (e.g., $50 \mathrm{~cm} \mathrm{~h}^{-1}$ in Fig. 2a ), we use the last estimated value of $k$ until $V$ falls again into a range in which Eqn. 14 can be applied.

[Insert Fig. 2 here]

\subsection{Validation of the DRM on trees}

\subsubsection{Lysimeter experiments}

We used whole-tree lysimetry to test the DRM, as well as the HRM, CHPM and Tmax methods. Measurements were made at the Centre for Carbon, Water and Food at the Camden Campus of the University of Sydney in Brownlow Hill, NSW, Australia $\left(34.03^{\circ} \mathrm{S}, 150.66^{\circ} \mathrm{E}\right)$ in $2016-2017$. Three E. cypellocarpasaplings, each in a large container $(0.9 \mathrm{~m}$ by $1.2 \mathrm{~m}$ by $0.9 \mathrm{~m})$, were placed on lysimeters capable of weighing up to 1200 $\mathrm{kg}$ (50 g resolution, Mettler Toledo). The three saplings were originally planted as seedlings in the containers in 2011. Irrigation was adjusted so that we could measure sap velocity across a range of water availabilities. Trees were initially irrigated 30 minutes (around $2.5 \mathrm{~L} \mathrm{~min}^{-1}$ ) twice a day for a month, and then reduced to 20 minutes twice a day, then to two minutes six times a day, and finally without any irrigation for several days. Transpiration was calculated from weight loss measured by the weighing lysimeters. Additional details regarding the lysimetry data analysis are provided in Methods S3 .

\subsubsection{Sap velocity probe construction and installation}

Each probe set comprises three temperature sensor probes and one heater probe. Each temperature sensor contained one thermistor (QTI Sensing Solutions, E320) inserted into an 18-gauge blunt tip needle. Thermistor sensing tips were coated in heat sink compound before inserting and then centered $1.5 \mathrm{~cm}$ from the distal end of the needle. Thermistor depths were fixed by placing a drop of low-viscosity cyanoacrylate glue in both the proximal and distal end of the needle. Each heater was made by feeding approximately $65 \mathrm{~cm}$ Manganin wire (Goodfellow Group Ltd., CU065822) through a 27.5-gauge hypodermic needle, leaving 3 to $5 \mathrm{~cm}$ of wire extending from the proximal end of the needle with the remainder (approximately $60 \mathrm{~cm}$ ) protruding from the distal end, and then winding the wire tightly around the outside of the needle until $3 \mathrm{~cm}$ of needle was covered with winding. Cyanoacrylate glue was then applied to the proximal section of winding to prevent further unwinding, and the needle's plastic base was removed by gripping the needle with pliers below the glued winding and bending it repeatedly at an angle of approximately 20 degrees until it fractured and could be pulled off the remaining wire. The resulting "heater core" was then dipped in heat sink compound and inserted into an 18-gauge needle. The total resistance of the heaters varied from 17 to $18.4 \mathrm{Ohms}$ and was insensitive to temperature between $00 \mathrm{C}$ and $700 \mathrm{C}$. The sensors and heaters were soldered to extension cables which were wired to an AM16-32B multiplexer (Campbell Scientific Inc., Logan, Utah) and relays respectively. Initiation of the heat pulses and the temperature recordings were controlled by a CR850 datalogger (Campbell Scientific).

Probes were inserted radially into the sapwood and parallel to one another, with the aid of a portable drill press (Kanzawa, K-801) and a rigid levelling plate made from angle iron and strapped to each tree. Temperature sensors were located at distances of $0.75 \mathrm{~cm}$ proximal (Probe \#1, $x_{1}=-0.75 \mathrm{~cm}$ ), $0.75 \mathrm{~cm}$ distal (Probe \#2, $x_{2}=+0.75 \mathrm{~cm}$ ) and $2.25 \mathrm{~cm}$ distal (Probe \#3, $x_{3}=+2.25 \mathrm{~cm}$ ) to the heater probe. One set of sensors was installed on each tree approximately $30 \mathrm{~cm}$ above the soil surface. A heat pulse of 7-16 s in duration was initiated every 15 or $30 \mathrm{~min}$ by applying $12 \mathrm{~V}$ across the heater probe wire, which induced a peak temperature rise of around $2 \mathrm{~K}$ in Probe \#2. The subsequent temperature change of each probe was recorded every second for 5 to $10 \mathrm{~min}$. All probe installations were wrapped with $15 \mathrm{~cm}$ thick polyester insulation and covered with Mylar-coated bubble wrap for insulation.

The temperature rise $\left(\delta_{\mathrm{i}}\right)$ was calculated by first computing the initial temperature of each probe as its average for $5 \mathrm{~s}$ before a given heat pulse. To account for drift in background temperature during the rise and decay of temperature following each heat pulse, we used the pchip function in Matlab to simulate 
changes in background temperature by smooth interpolation between each successive pre-heat-pulse initial temperature, and then subtracted the resulting changes in background temperature from each time course of temperature to give $\delta_{\mathrm{i}}$.

Heat pulse velocities were converted to sap velocity following Burgess et al. (2001). The sapwood properties including $\rho$ b and $m c$ were measured by tree core samples during and at the end of the experiments (see sapwood properties in Table S1). Whole-tree sap flow $\left(\mathrm{kg} \mathrm{h}^{-1}\right)$ was determined as the product of sap velocity $\left(\mathrm{cm} \mathrm{h}^{-1}=\mathrm{cm}^{3}{ }_{\text {sap }} \mathrm{cm}^{-2}\right.$ sapwood $\left.\mathrm{h}^{-1}\right)$, sapwood cross sectional area $\left(\mathrm{cm}^{2}\right.$ sapwood $)$ and a conversion factor $\left(10^{-3}\right.$ $\mathrm{kg} \mathrm{cm}^{-3}$ sap). The diameters of the eucalypt trees (\#1,2 and 3) were 8.2, 8.4 and $10.0 \mathrm{~cm}$, respectively, at the height of each heater probe installation. As we did not attempt to account for radial or azimuthal variation in sap velocity (Lopez-Bernal, Alcantara, Testi, \& Villalobos, 2010; Phillips, Oren, \& Zimmermann, 1996; Poyatos, Cermak, \& Llorens, 2007), we focused on consistency between the dynamics of water loss as measured by lysimetry and that inferred by sap flow methodologies, rather than quantifying absolute sap velocity. We thus empirically adjusted whole-tree sap flow estimates using a scaling factor for each tree that equalized peak midday flow for lysimetry and sap flow methods. Scaling factors were close to constant from February through May 2016 (see Table S3). Comparisons of sap flow methods to lysimetry are best made when flows of water into or out of stores in the stem are least, typically during the middle of the day (greatest in early morning and late afternoon (Thomas N. Buckley et al., 2011; Chuang, Oren, Bertozzi, Phillips, \& Katul, 2006; Deng et al., 2017).

3 Results

\subsection{Theoretical testing}

\subsubsection{Operational procedures for DRM}

We calculated $V$ DRM by averaging values (measured at $1 \mathrm{~Hz}$ ) for window sizes varying between 5 and 100 $\mathrm{s}$, based on a central time point at which either $\sigma_{12}$ or $\sigma_{23}$ was smallest. Monte Carlo simulations indicated that the optimal window size was inversely related to sap velocity (Fig. 3 ). For example, standard errors were least using a window width of 80-100 s for a true sap velocity of $30 \mathrm{~cm} \mathrm{~h}^{-1}$, but 20-40 s when velocities were $80 \mathrm{~cm} \mathrm{~h}^{-1}$ (Fig. 3b,e ). Time windows for the least biased estimates of $V$ did not overlap as indicated by the SE at $V=80 \mathrm{~cm} \mathrm{~h}^{-1}$ when comparing time windows of 20 and $80 \mathrm{~s}$ (Fig. 3e ,f ). This is due to the assumption of an instantaneous heat pulse in the Marshall Model, from which all heat-pulse based methods are derived (see Discussion).

[Insert Fig. 3 here]

In theory, window sizes of $80 \mathrm{~s}$ can be used, but in practice the quality of recorded temperature data deteriorates as temperatures level off and noise thus becomes increasingly prominent. For example, if we exclude temperature rises of less than $0.015 \mathrm{~K}$ (3 times the standard deviation of temperature noise due to sensor resolution), sap velocities $>80 \mathrm{~cm} \mathrm{~h}^{-1}$ could not be deciphered using a $100 \mathrm{~s}$ window. Optimal window sizes generally decrease as flow rates increase. To simplify, we suggest a fixed window of $40 \mathrm{~s}$ for $V$ DRM calculations - the same window size as recommended for the HRM.

In minimizing SEs, the DRM algorithm identifies both the optimal size and timing of the averaging window. There is a distinct transition of optimal window size and timing in the range of velocities at which the intrinsic uncertainties of $V_{12}$ and $V_{23}$ are similar, which occurs at around $\sim 20 \mathrm{~cm} \mathrm{~h}^{-1}$. At lower sap velocities, $V$ 12 is less uncertain than $V_{23}$ (hence $V_{\text {DRM }}=V_{12}$, Eqn. 7 ), giving an optimal averaging window $40 \mathrm{~s}$ wide and centred between 60 and $70 \mathrm{~s}$ (Fig.4 ) - very similar to the averaging window commonly used for the HRM ( $40 \mathrm{~s}$ wide and centered at $80 \mathrm{~s}$, see Chen et al. (2012)). At intermediate sap velocities, $V_{23}$ is less uncertain than $V_{12}$ (hence $V_{\text {DRM }}=V_{23}$ ), and the optimal averaging window is centered at $>200 \mathrm{~s}$ - roughly when the temperature traces for Probe \#2 and \#3 intersect (see blue and red lines in Fig. 4 ). Note that the velocity at which the transition from $V_{12}$ to $V_{23}$ occurs will depend on conditions and will differ with probe positions and heat pulse strength and length. For example, greater heat intensity $\left(Q / t_{0}\right)$ will lead to a transition at greater flux. 
[Insert Fig. 4 here]

3.1.2 Performance of the heat-pulse based methods

Simulation results with synthetic data (See the generation procedure in SI on Simulations S1 \& S2 ) are shown in Fig.5. Among all four methods, the DRM calculation of $V$ is consistently closest to the true value used to generate the synthetic data, deviating little from the true value for high $(0.2 \%$ deviation at $80 \mathrm{~cm}$ $\left.\mathrm{h}^{-1}\right)$, low $\left(0.5 \%\right.$ at $\left.20 \mathrm{~cm} \mathrm{~h}^{-1}\right)$ and negative sap velocities $\left(1.6 \%\right.$ at $\left.-10 \mathrm{~cm} \mathrm{~h}^{-1}\right)$. The coefficient of variation of estimates was also smallest for the DRM (e.g., $2 \%$ at $20 \mathrm{~cm} \mathrm{~h}^{-1}$ and $0.5 \%$ at $80 \mathrm{~cm} \mathrm{~h}^{-1}$ ). The HRM performs well at negative to low sap velocities $\left(<40 \mathrm{~cm} \mathrm{~h}^{-1}\right)$ but systematically underestimates true sap velocity when velocity is high. The CHPM only performs well at intermediate sap velocities $\left(20-40 \mathrm{~cm} \mathrm{~h}^{-1}\right)$, yielding a widely diverging range of estimates when true sap velocities are high, low or negative. The poor performance of the HRM and CHPM at high sap velocities is caused by very small temperature rises at the proximal temperature sensor $\left(\delta_{1}\right)$. Calculations that depend on $\delta_{1}$ become unreliable under such conditions (Fig.S3a ). The CHPM also performs poorly when sap velocity is low because it relies on precise determination of the time when $\delta_{1}=\delta_{3}: \delta_{3}$ is small when sap velocity is low, leading to increased error (Fig. S3b ). The Tmax method is based on timing of peak temperature rise and is thus sensitive to noise at relatively low sap velocities (e.g., $35 \%$ coefficient of variation at $20 \mathrm{~cm} \mathrm{~h}^{-1}$ ).

[Insert Fig. 5 here]

The applicable range of the HRM depends on the magnitude of error in measured temperature rise (See Fig. S4 $)$, which in turn depends on the precision of the temperature sensor $\left(\sigma_{\mathrm{T}}\right)$ and the amount of heat generated during the heat pulse. The useful range of the HRM could be extended by increasing heat pulse duration.

\subsubsection{Sensitivity to the $\mathrm{k}$}

Among the four heat pulse methods, the HRM was the most sensitive to uncertainty in $k$. Calculations of $V$ are directly proportional to $k$ using the HRM. Estimates of $V$ from the DRM are also sensitive to $k$ at low sap velocities $\left(<20 \mathrm{~cm} \mathrm{~h}^{-1}\right)$ because $V$ DRM is dominated by $V_{12}\left(V_{\text {HRM }}\right.$, Eqn. 4$)$ under such conditions (Fig. 6 ). However, when sap velocity is high, $V$ DRM equals $V_{23}$, which is much less sensitive to $k$; this is because $V_{23}$ is the sum of two terms, of which only one depends directly on $k$ (Eqn. 6 ). The CHPM is completely insensitive to uncertainty in $k$, while the Tmax method is strongly influenced by noise at high sap velocities. Using $k$ as estimated using either Eqn. 13 or Eqn. 14considerably improves the accuracy of the DRM (and HRM) at low sap velocities.

[Insert Fig. 6 here]

\subsection{Validating DRM with the lysimetry experiment}

Peak transpiration fluxes were 5.5, 6 and $7 \mathrm{~kg} \mathrm{~h}^{-1}$, for Trees \#1, \#2 and \#3, respectively, from Feb to May 2016. The peak temperature rise of Probe \#2 was around $2 \mathrm{~K}$ at midday and $0.6 \mathrm{~K}$ at night. The peak sap velocity calculated by the DRM was $>60 \mathrm{~cm} \mathrm{~h}^{-1}$ for Tree \#1, $80 \mathrm{~cm} \mathrm{~h}^{-1}$ for Tree \#2 and $100 \mathrm{~cm} \mathrm{~h}^{-1}$ for Tree \#3.

The DRM reproduced diel patterns of sap flow measured by lysimetry under a wide range of flow conditions, from negligible flows at night to very large and fluctuating flows (see Fig. $\mathbf{7}$ for the sap flow, Fig. 8 for the sap velocity of Tree \#3 and Fig. S5 for all the three trees). The HRM, by contrast, was unable to capture sap velocity $>25 \mathrm{~cm} \mathrm{~h}^{-1}\left(>2 \mathrm{~kg} \mathrm{~h}^{-1}\right.$, Fig. 7 ). While better than the HRM in capturing large sap velocities (Fig. 7,8 ), the CHPM also failed when velocity was either very high or very low (see Fig.8 ). The Tmax method failed to capture sap velocities $<20 \mathrm{~cm} \mathrm{~h}^{-1}$. To match peak velocity measured by lysimetry (see Table S3 ), scaling factors for Tmax had to be increased with time. For example, scaling factors increased 1.3-fold from Feb to Apr, and 1.6-fold from Feb to May. The sensitivity of the Tmax method to noise and probe alignment requires constant adjustment of scaling factors as trees grow.

[Insert Fig. 7 here] 
By comparison with lysimetry data, heat-based methods of measuring sap velocity show a lag of 10 minutes. A likely explanation is that water stored in stems and branches contributes to the transpiration stream in the early morning - stores that are replenished via root water uptake in the late afternoon.

[Insert Fig. 8 here]

4 Discussion

4.1 DRM vs. other heat-pulse based methods

The double-ratio method (DRM) presented here was more robust than other common heat pulse methods (HRM, CHPM and Tmax) across a wide range of sap velocity, in both theoretical and experimental tests. In theoretical tests, the DRM produced the least bias and smallest variance among the four methods. In experimental tests, the DRM accurately tracked diel trends in tree water use (as measured by lysimetry) from $0-7 \mathrm{~kg} \mathrm{~h}^{-1}$ or $0-100 \mathrm{~cm} \mathrm{~h}^{-1}$.

The applicable upper limit for the HRM can be roughly estimated from Eqn. 4, given the resolution of temperature sensors and peak rise in temperature. For example, if we assume:

- that the temperature rise at the proximal probe $\left(\delta_{1}\right)$ is reliable if its output is at least 3 times the standard deviation of temperature noise due to sensor resolution (approximately $0.005 \mathrm{~K}$ in our experiment), so that values of $\delta_{1}$ below $0.015 \mathrm{~K}$ are excluded; and

- that the largest observed value of the temperature rises at the first downstream probe $\left(\delta_{2}\right)$ is $1.0 \mathrm{~K}$,

then with a probe spacing of $1.5 \mathrm{~cm}$ and $k=0.0025 \mathrm{~cm}^{2} \mathrm{~s}^{-1}$, the upper limit of velocity that the HRM can estimate is,

$$
V_{H R M, \max }=\frac{2 \cdot 0.0025 \mathrm{~cm}^{2} \mathrm{~s}^{-1}}{1.5 \mathrm{~cm}} \ln \left(\frac{1 K}{0.015 K}\right)=0.014 \mathrm{~cm} \mathrm{~s}^{-1}\left(50 \mathrm{~cm} \mathrm{~h}^{-1}\right) .
$$

In practice, the minimum uncertainty in $\delta_{1}$ is likely larger than the sensor resolution due to other factors (e.g., background fluctuations, drifts in temperature). This limit could be increased by reducing probe spacing or increasing the size of the heat pulse. However, closer spacing magnifies relative errors caused by imperfect alignment of probes during installation.

The CHPM was unable to detect high sap velocities because, like the HRM, it is limited by uncertainty in $\delta$ 1. The CHPM also fails at low sap velocities because the intrinsic uncertainty in the "crossover point" of $\delta$ 1 and $\delta_{3}$ is greater. Both the CHPM and the Tmax methods are inherently incapable of detecting negative sap velocities (reverse flows). Testi and Villalobos (2009) suggested the resolution of the CHPM could be improved using an empirical calibration function (Vandegehuchte \& Steppe, 2012c), albeit this requires study and species-specific solutions.

Pearsall et al. (2014) obtained estimates of sap velocity $>200 \mathrm{~cm} \mathrm{~h}^{-1}$ by supplementing the HRM with the CHPM. Those velocities far exceed values that we were able to detect using the CHPM $\left(\sim 40-50 \mathrm{~cm} \mathrm{~h}^{-1}\right)$. Given that Pearsall et al. (2014) used temperature sensors and dataloggers with similar resolution to ours, and heater probes with similar resistances $(18 \Omega)$, this discrepancy in maximum velocities may be due to wider probe spacing used in the present study $(1.5 \mathrm{~cm}$ vs $1.2 \mathrm{~cm}$ used by Pearsall et al. 2014). To assess this possibility, we can use Eqn. 1 to quantify the effect of probe spacing on the maximum temperature rise that one would expect to occur at the proximal probe (Probe \#1). Suppose $\rho=1.08[?] 10^{3} \mathrm{~kg} \mathrm{~m}^{-3}, c=$ $2.8[?] 10^{3} \mathrm{~J} \mathrm{~kg}^{-1} \mathrm{~K}^{-1}, Q=1370 \mathrm{~J} \mathrm{~m}^{-1}$ (a $3.5 \mathrm{~cm}$ probe with $18 \Omega$ resistance and 6 s pulse at $12 \mathrm{~V}$ ), and $k$ $=0.0025 \mathrm{~cm}^{2} \mathrm{~s}^{-1}$; then, at a true heat pulse velocity of $100 \mathrm{~cm} \mathrm{~h}^{-1}\left(0.028 \mathrm{~cm} \mathrm{~s}^{-1}\right), \delta_{1}$ should reach 0.0099 $\mathrm{K}$ for a probe spacing of $1.2 \mathrm{~cm}$, and $0.0014 \mathrm{~K}$ for $1.5 \mathrm{~cm}$. This difference results from the exponential dependence of temperature rise on probe spacing (Eqn. 1 ). We suggest that superior performance of the DRM compared to the CHPM at high sap velocities is likely due to wider probe spacing (i.e. compared to that used by Pearsall et al. (2014)). Wider spacing has the advantage that a given absolute error of probe alignment during installation will cause a smaller error in calculated sap velocity. 
The DRM has other advantages. Most importantly, the measurement principle (Eqn. 2 ) is the same across all sap velocities. Switching measurement principles, as required if HRM is used for slow sap velocities and the CHPM for fast sap velocities, creates logistic problems and carries the risk of greater variation due to edaphic conditions. Secondly, the DRM provides a theoretical basis for identifying the optimal time window in which to average estimates of sap velocity. We found an optimal window for E. cypellocarpa of between 50 and $120 \mathrm{~s}$ (see Fig. S6 ), which is approximately equal to theoretically calculated values (Fig. 4 ) and similar to the window used for the HRM. Thirdly, the DRM is less sensitive to noise than the CHPM, because the latter relies on a single intersection point, whereas the former averages data over a longer time period. Finally, the DRM is relatively insensitive to uncertainty in the value of $k$ when $V>20 \mathrm{~cm} \mathrm{~h}^{-1}$ because $V$ DRM $=V_{23}$ (Eqn.6 ) at high sap velocities, and the term involving $k$ in Eqn. 6 becomes small compared to the term that involvest.

\subsection{Impact of the finite heat pulse length}

Following Marshall's original model, the assumption of an instantaneous heat pulse results in biased estimates of sap velocity in most methods. A small negative bias is evident in both the DRM- and HRM-based velocity estimates. The bias of the DRM increases from $-0.03 \%$ when $V=30 \mathrm{~cm} \mathrm{~h}^{-1}$ to $-0.2 \%$ when $V=80 \mathrm{~cm} \mathrm{~h}^{-1}$ (Fig. 9 ). A larger bias is evident using the CHPM (underestimates velocity by $9 \%$ at $30 \mathrm{~cm} \mathrm{~h}^{-1}$ ) because of reliance on the precise timing where $\delta_{1}=\delta_{3}$. Its high sensitivity to $t_{0}$ is also recognized in a data synthesis study of Flo et al. (2019). The Tmax method can be modified to account for $t_{\mathbf{0}}$ (Kluitenberg \& Ham, 2004), thus eliminating this bias. In practice, Tmax-based sap velocity estimates are highly uncertain when velocity is high, due to sensitivity to noise (Fig. 5e ). Shifting $t_{\mathbf{0}}$ helps mitigate the impact of the finite heat pulse length across methods, resulting in negligible bias for the DRM (Fig. 9 ).

[Insert Fig. 9 here]

\subsection{Misalignment correction}

Misalignment of probes is a major source of uncertainty for heat-pulse techniques. It affects all methods and can bias inferred sap velocity either positively or negatively. Burgess et al. (2001) suggested three options to correct for misalignment in the HRM: forcing the calculated sap velocity to equal zero under conditions when the true sap velocity is known to be zero (e.g., after an extended period at $100 \% \mathrm{RH}$ ), by correcting either the upstream $\left(\begin{array}{ll}x_{1}\end{array}\right)$ or downstream $\left(\begin{array}{ll}x_{2}\end{array}\right)$ probe locations, or by averaging both of the resulting corrected values, assuming misalignment for either probe is equally likely ([?] $x_{1}=[?] x_{2}$, where [?] $x_{i}$ is the misalignment correction for Probe \# $i$ ). While all three methods result in matched calculated and measured sap velocities under "zero-flow" conditions, they do not yield consistent day-time sap velocities (Fig. 10 ).

[Insert Fig. 10 here]

The HRM requires a known value of $k$ to correct errors due to probe misalignment. Typically, a constant $k$ is assumed. Burgess et al. (2001) used the Tmax method (Eqn. 15) to calculate $k$. This is a somewhat circular procedure because the Tmax method requires knowledge of probe locations. It would be preferable to concurrently solve for all three unknowns -[?] $x_{1},[?] x_{2}$ and $k-$ as shown by Chen et al. (2012). Such a calibration approach may not be achievable unless constrained with assumptions or additional calculations (e.g. sap velocity independently inferred via an empirical function in Chen et al. (2012)). We suggest an alternative calibration procedure. First, alignment is checked using the HRM method suggested by Burgess et al. (2001). Second, the non-unique solution is constrained by comparing velocities using the CHPM, which is independent of $k$. Finally, $k$ is identified with the Tmax method under zero flow conditions (see the misalignment calibration procedures in Methods S4 ). Fig. 11 below compares such calibration results. When the average solution is chosen from the HRM method, sap velocities estimated using the DRM match well with those estimated using the CHPM. In this scenario, any misalignment is well corrected (CHPM is sensitive to misalignment) and $k$ is appropriately estimated (DRM is sensitive to $k$ at low flow).

The three-probe approach used by the DRM allows diagnosis of misalignment corrections. Combined with calculations based on the CHPM, it also allows for detemination of both $k$ and misalignment under moderate 
conditions (e.g. typical day-time).

[Insert Fig. 11 here]

5 Conclusions

We present a new heat-pulse-based method, the Double-Ratio Method (DRM), to calculate sap velocity in woody plants. We demonstrate both theoretically and experimentally that the DRM can effectively measure a broader range of sap velocities than other common heat-pulse based methods. Like an earlier approach that combined the HRM and CHPM, the DRM computes two distinct estimates of sap velocity at each time point; however, the DRM has several advantages over the combination of the HRM and CHPM, including a theoretical basis for selecting between the two velocity estimates and identifying the optimal times for averaging data, and a reduced sensitivity to noise at high velocities.

Acknowledgements

This work was supported by the Australian Research Council (LP130100183), the International Wheat Yield Partnership (IWYP, project 89) through a grant from the Grains Research and Development Corporation (GRDC, US00082), the National Science Foundation (Awards \#1557906 and 1951244), Almond Board of California and the USDA National Institute of Food and Agriculture, Hatch project 1016439.

\section{Author contributions}

MA and TB planned, designed and coordinated the research. TB developed the DRM algorithm and designed the probes for the experiment, data interpretation. ZD conducted the numerical simulations, lysimetry experiment, data collection, analysis and interpretation. HV and MG performed part of the experiment and data collection. ZD and TB wrote the manuscript. All the authors contributed critically to the drafts and gave final approval for publication.

\section{Conflict of interest}

The authors have no conflict of interest.

\section{References}

Bleby, T., McElrone, A., \& Burgess, S. (2008). Limitations of the HRM: great at low flow rates, but not yet up to speed. Paper presented at the 7th International Workshop on Sap Flow: Book of Abstracts'.(International Society of Horticultural Sciences: Seville, Spain).

Buckley, T. N., Turnbull, T. L., Pfautsch, S., \& Adams, M. A. (2011). Nocturnal water loss in mature subalpine Eucalyptus delegatensis tall open forests and adjacent E. pauciflora woodlands. Ecology and Evolution, 1 (3), 435-450. doi:10.1002/ece3.44

Buckley, T. N., Turnbull, T. L., Pfautsch, S., Gharun, M., \& Adams, M. A. (2012). Differences in water use between mature and post-fire regrowth stands of subalpine Eucalyptus delegatensis R. Baker.Forest Ecology and Management, 270 , 1-10.

Burgess, S. S., Adams, M. A., Turner, N. C., Beverly, C. R., Ong, C. K., Khan, A. A., \& Bleby, T. M. (2001). An improved heat pulse method to measure low and reverse rates of sap flow in woody plants. Tree Physiology, 21 (9), 589-598.

Cermak, J., Kucera, J., Bauerle, W. L., Phillips, N., \& Hinckley, T. M. (2007). Tree water storage and its diurnal dynamics related to sap flow and changes in stem volume in old-growth Douglas-fir trees. Tree Physiology, 27 (2), 181-198. doi:10.1093/treephys/27.2.181

Chen, X., Miller, G. R., Rubin, Y., \& Baldocchi, D. D. (2012). A statistical method for estimating wood thermal diffusivity and probe geometry using in situ heat response curves from sap flow measurements. Tree Physiology, 32 (12), 1458-1470. 
Chuang, Y. L., Oren, R., Bertozzi, A. L., Phillips, N., \& Katul, G. G. (2006). The porous media model for the hydraulic system of a conifer tree: Linking sap flux data to transpiration rate. Ecological Modelling, 191 (3-4), 447-468. doi:10.1016/j.ecolmodel.2005.03.027

Clearwater, M., Meinzer, F., Andrade, J., Goldstein, G., \& Holbrook, N. (1999). Potential errors in measurement of nonuniform sap flow using heat dissipation probes. Tree Physiology, 19 (10), 681-687.

Cohen, Y., Fuchs, M., \& Green, G. (1981). Improvement of the heat pulse method for determining sap flow in trees. Plant, Cell \& Environment, 4 (5), 391-397.

Deng, Z., Guan, H., Hutson, J., Forster, M. A., Wang, Y., \& Simmons, C. T. (2017). A vegetation-focused soil-plant-atmospheric-continuum model to study hydrodynamic soil-plant water relations. Water Resources Research .

Edwards, W. R. N., Becker, P., \& Èermák, J. (1996). A unified nomenclature for sap flow measurements. Tree Physiology, 17 (1), 3.

Flo, V., Martinez-Vilalta, J., Steppe, K., Schuldt, B., \& Poyatos, R. (2019). A synthesis of bias and uncertainty in sap flow methods.Agricultural and Forest Meteorology, 271 , 362-374. doi:10.1016/j.agrformet.2019.03.012

Granier, A. (1985). Une nouvelle méthode pour la mesure du flux de sève brute dans le tronc des arbres. Paper presented at the Annales des Sciences forestières.

Green, S., \& Clothier, B. (1988). Water use of kiwifruit vines and apple trees by the heat-pulse technique. Journal of Experimental Botany, 39 (1), 115-123.

Green, S., Clothier, B., \& Jardine, B. (2003). Theory and practical application of heat pulse to measure sap flow. Agronomy Journal, 95 (6), 1371-1379.

Kluitenberg, G. J., \& Ham, J. M. (2004). Improved theory for calculating sap flow with the heat pulse method. Agricultural and Forest Meteorology, 126 (1), 169-173.

Lopez-Bernal, A., Alcantara, E., Testi, L., \& Villalobos, F. (2010). Spatial sap flow and xylem anatomical characteristics in olive trees under different irrigation regimes. Tree Physiology, 30 (12), 1536-1544. doi:10.1093/treephys/tpq095

López-Bernal, Á., Alcántara, E., \& Villalobos, F. J. (2014). Thermal properties of sapwood of fruit trees as affected by anatomy and water potential: errors in sap flux density measurements based on heat pulse methods. Trees, 28 (6), 1623-1634.

Marshall, D. (1958). Measurement of sap flow in conifers by heat transport. Plant Physiology, 33 (6), 385.

Nadezhdina, N., Cermak, J., \& Nadezhdin, V. (1998). Heat field deformation method for sap flow measurements. Paper presented at the Measuring sap flow in intact plants. Proceedings of 4th International Workshop, Židlochovice, Czech Republic, IUFRO Publ. Brno, Czech Republic: Mendel University.

Pearsall, K. R., Williams, L. E., Castorani, S., Bleby, T. M., \& McElrone, A. J. (2014). Evaluating the potential of a novel dual heat-pulse sensor to measure volumetric water use in grapevines under a range of flow conditions. Functional Plant Biology, 41 (8), 874-883. doi:https://doi.org/10.1071/FP13156

Pfautsch, S., Keitel, C., Turnbull, T. L., Braimbridge, M. J., Wright, T. E., Simpson, R. R., . . Adams, M. A. (2011). Diurnal patterns of water use in Eucalyptus victrix indicate pronounced desiccation-rehydration cycles despite unlimited water supply. Tree Physiology, 31 (10), 1041-1051. doi:10.1093/treephys/tpr082

Phillips, N., Oren, R., \& Zimmermann, R. (1996). Radial patterns of xylem sap flow in non-, diffuse- and ringporous tree species.Plant Cell and Environment, 19 (8), 983-990. doi:10.1111/j.1365-3040.1996.tb00463.x 
Poyatos, R., Cermak, J., \& Llorens, P. (2007). Variation in the radial patterns of sap flux density in pubescent oak (Quercus pubescens) and its implications for tree and stand transpiration measurements. Tree Physiology, 27 (4), 537-548. doi:10.1093/treephys/27.4.537

Steppe, K., Vandegehuchte, M., Tognetti, R., \& Mencuccini, M. (2015). Sap flow as a key trait in the understanding of plant hydraulic functioning. Tree Physiology, 35 (4), 341-345. doi:10.1093/treephys/tpv033

Testi, L., \& Villalobos, F. J. (2009). New approach for measuring low sap velocities in trees. Agricultural and Forest Meteorology, 149 (3), 730-734.

Vandegehuchte, M. W., \& Steppe, K. (2012a). A triple-probe heat-pulse method for measurement of thermal diffusivity in trees.Agricultural and Forest Meteorology, 160 , 90-99.

Vandegehuchte, M. W., \& Steppe, K. (2012b). Improving sap flux density measurements by correctly determining thermal diffusivity, differentiating between bound and unbound water. Tree Physiol, 32 (7), 930-942.

Vandegehuchte, M. W., \& Steppe, K. (2012c). Sapflow+: a four-needle heat-pulse sap flow sensor enabling nonempirical sap flux density and water content measurements. New Phytologist, 196 (1), 306-317.

Wilson, K. B., Hanson, P. J., Mulholland, P. J., Baldocchi, D. D., \& Wullschleger, S. D. (2001). A comparison of methods for determining forest evapotranspiration and its components: sap-flow, soil water budget, eddy covariance and catchment water balance. Agricultural and Forest Meteorology, 106 (2), 153-168.

Supporting Information

The supporting information includes Methods S1 to S4, Figure S1-S6, Table S1-S3, Notes S1. Methods S3 includes Figure S7, S8 \& S9. 


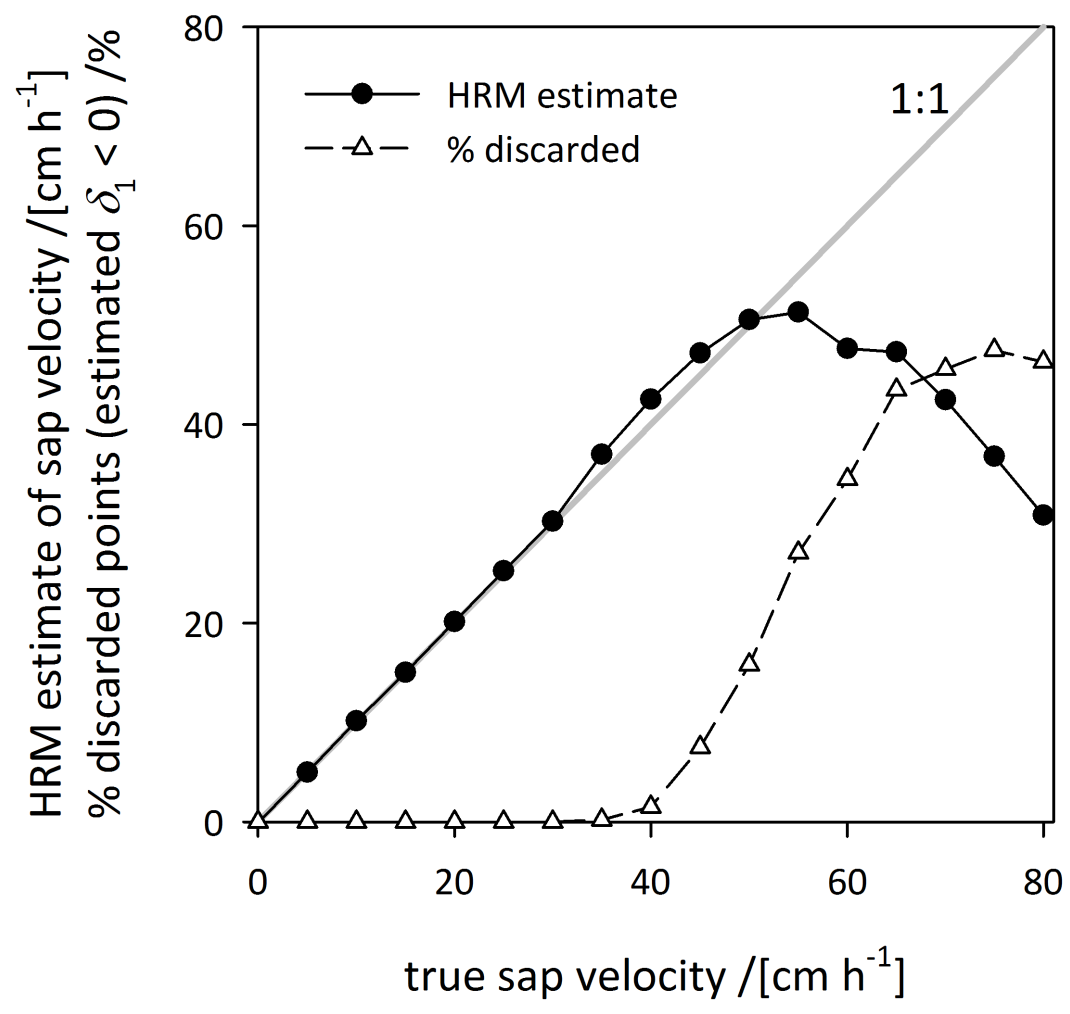



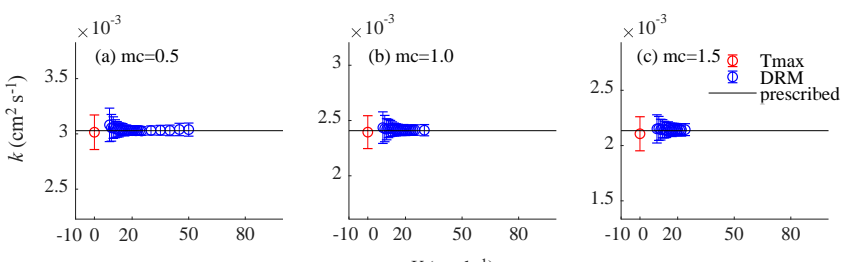

Figure 2: $k$ estimation with the DRM (blue) and the Tmax (red). Error bars show the standard deviations of the calculated $k$ with 1000 Monte Carlo samplings of the Gaussian errors, the black line shows the prescribed $k$ at various moisture contents ((a): $m c=0.5 \mathrm{~g} \mathrm{~g}^{-1}$; (b): $1.0 \mathrm{~g} \mathrm{~g}^{-1}$; (c): $\left.1.5 \mathrm{~g} \mathrm{~g}^{-1}\right)(k$ vs. $m c$ prescribed $k$ at various moisture contents $\left((\mathrm{a}): m c=0.5 \mathrm{~g} \mathrm{~g}^{-1} ;(\mathrm{b}): 1.0 \mathrm{~g} \mathrm{~g}^{-1}\right.$; (c):
relation follows the empirical function of Vandegehuchte and Steppe (2012b)). 


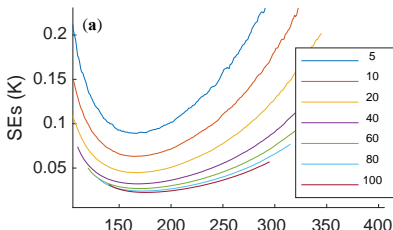

$\begin{array}{llllll}150 & 200 & 250 & 300 & 350 & 400\end{array}$

window center (seconds after heat pulse)

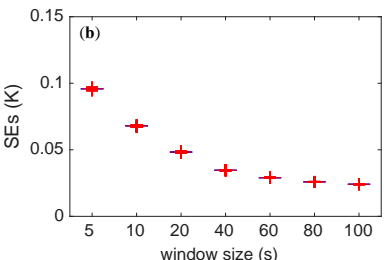

window size (s)

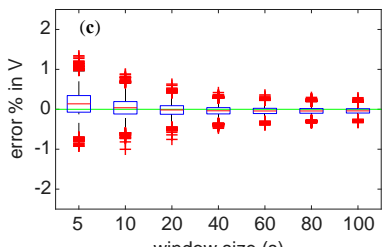

window size (s)

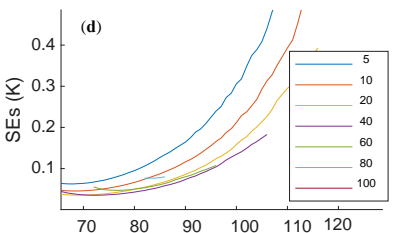

$\begin{array}{llllll}70 & 80 & 90 & 100 & 110 & 120\end{array}$

window center (seconds after heat pulse)
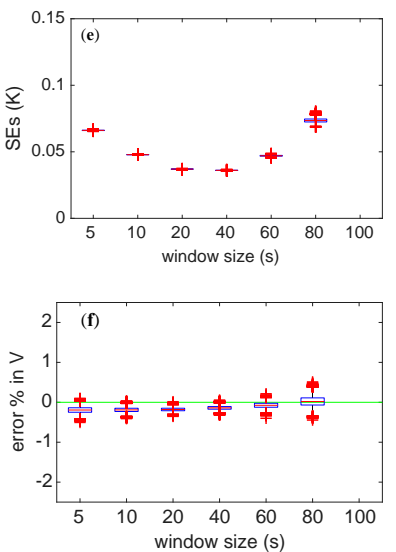

Figure 3: The standard errors (SEs) of averaging $V_{\text {DRM }}$ over various sized windows are shown in (a,d) with their corresponding central time points on the $x$ axis, (b,e) illustrate the distribution of SEs from 10,000 simulations in relation to the averaging window size and the distribution of the estimation errors (\%) in $V_{\text {DRM }}$ to the width of the averaging window are shown in (c,f). True sap velocity in a-c was set to $30 \mathrm{~cm} \mathrm{~h}^{-1}$ and d-f was $80 \mathrm{~cm} \mathrm{~h}^{-1}$. The legend values (5 to 100) for (a,d) specify width of the averaging window in seconds. The blue boxes (b,c,e,f) have upper and lower edges defined by the 25th and 75th percentiles of 10,000 runs and contain median values denoted by the red lines. The red crosses are the outliers greater than $2.7 \sigma$ from the mean. 


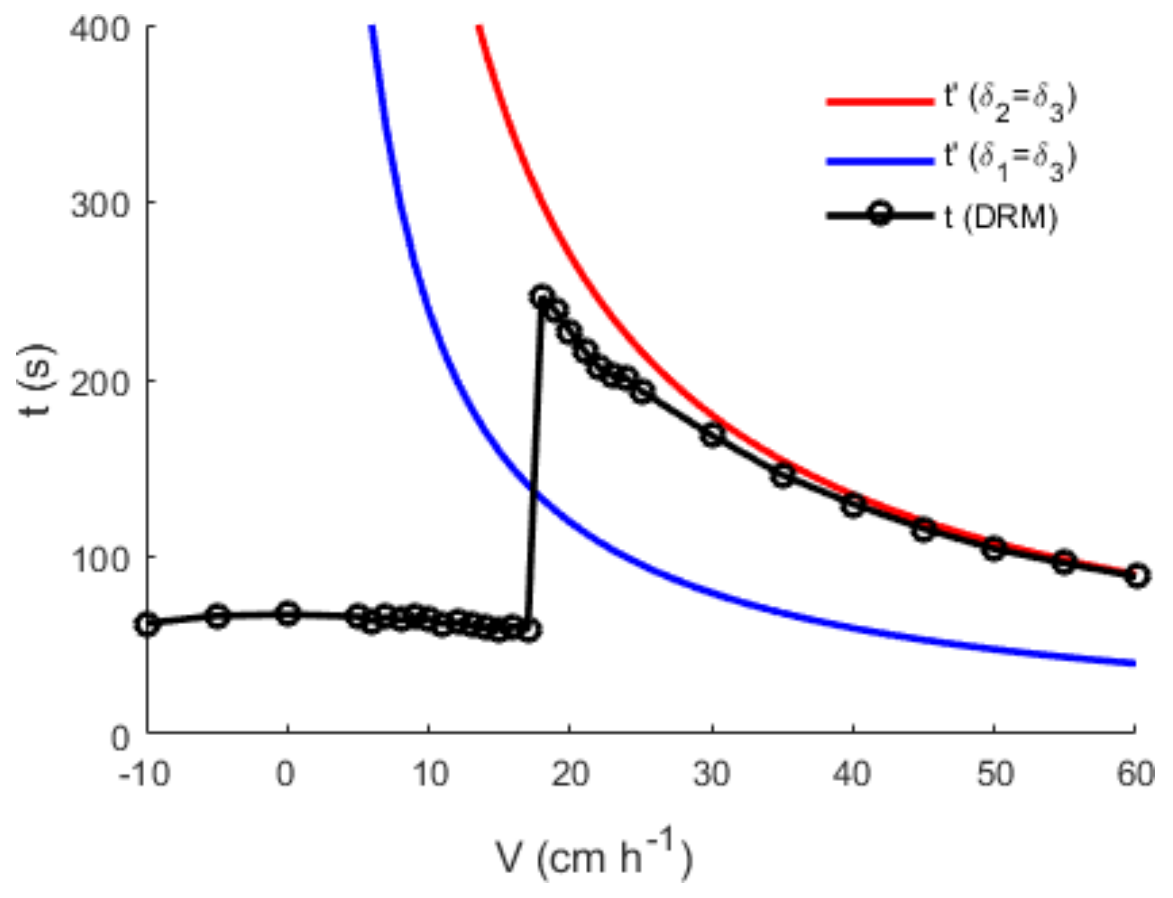



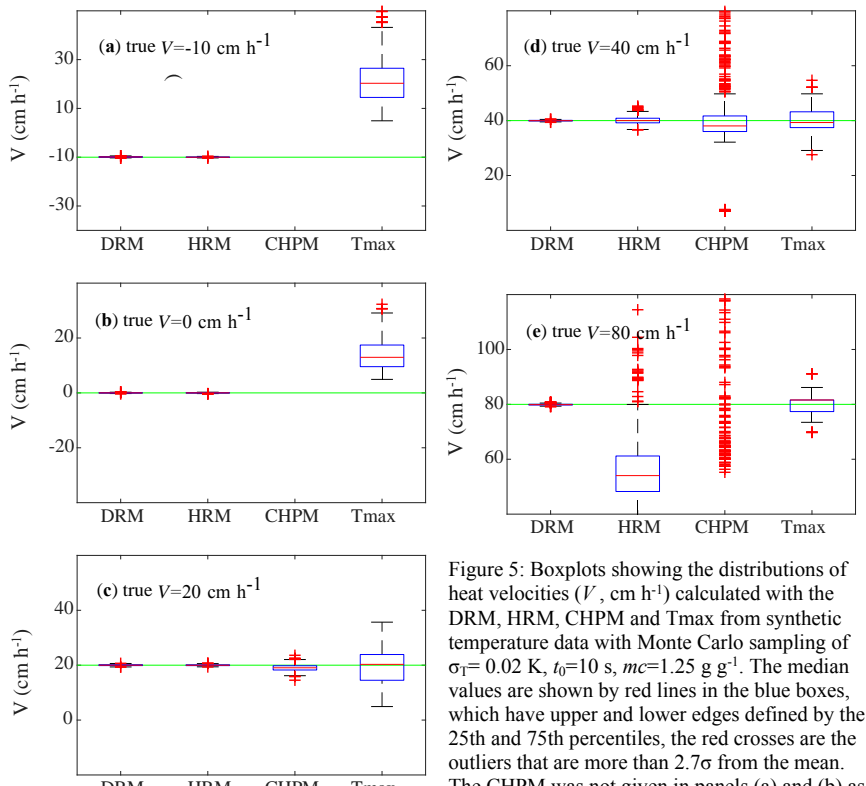

Figure 5: Boxplots showing the distributions of heat velocities $\left(V, \mathrm{~cm} \mathrm{~h}^{-1}\right)$ calculated with the

DRM, HRM, CHPM and Tmax from synthetic temperature data with Monte Carlo sampling of $\sigma_{\mathrm{T}}=0.02 \mathrm{~K}, t_{0}=10 \mathrm{~s}, m c=1.25 \mathrm{~g} \mathrm{~g}^{-1}$. The median values are shown by red lines in the blue boxes, which have upper and lower edges defined by the 25 th and 75 th percentiles, the red crosses are the outliers that are more than $2.7 \sigma$ from the mean.

DRM HRM CHPM Tmax The CHPM was not given in panels (a) and (b) as it could not resolve the negative to low flow. 

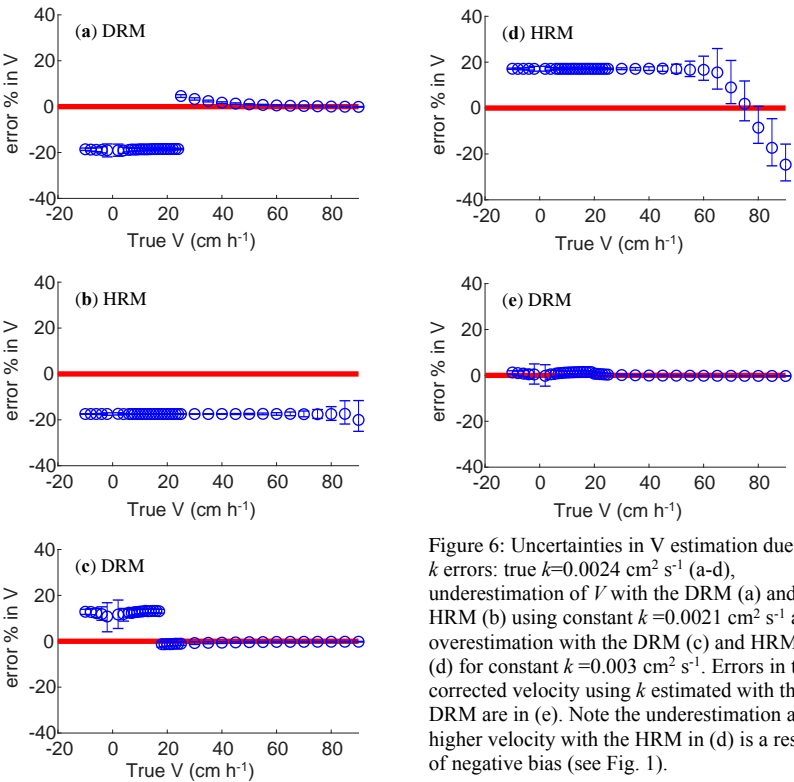

Figure 6: Uncertainties in $\mathrm{V}$ estimation due to $k$ errors: true $k=0.0024 \mathrm{~cm}^{2} \mathrm{~s}^{-1}$ (a-d),

underestimation of $V$ with the DRM (a) and

HRM (b) using constant $k=0.0021 \mathrm{~cm}^{2} \mathrm{~s}^{-1}$ and

overestimation with the DRM (c) and HRM

(d) for constant $k=0.003 \mathrm{~cm}^{2} \mathrm{~s}^{-1}$. Errors in the

corrected velocity using $k$ estimated with the

DRM are in (e). Note the underestimation at

higher velocity with the HRM in (d) is a result

of negative bias (see Fig. 1). 

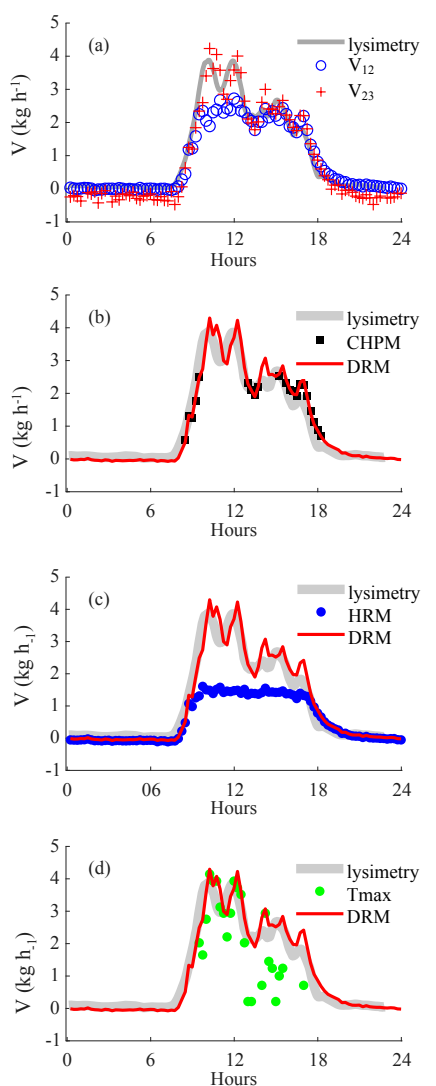

Figure 7: Comparison of lysimeter data (grey lines) with sap flow calculated using the DRM (red line) CHPM (black line), HRM

(blue line) and Tmax (green line), an example for Tree \#3 (on day 18/4/2016). 

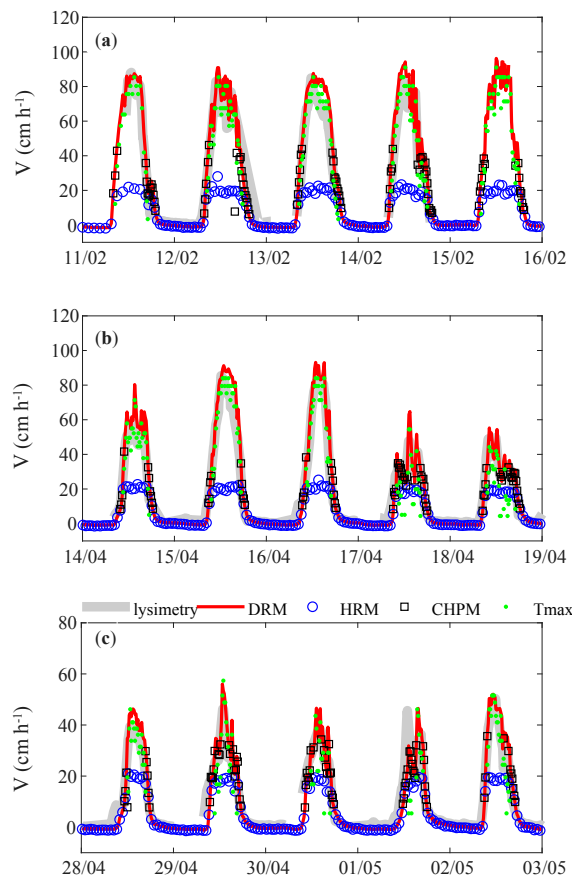

Figure 8: The sap velocity calculated with DRM and othe heat-pulse based methods over the months for tree 3 , sap flux of all trees are shown in Figure S5. x-axis is date in the format of dd/mm in 2016. 

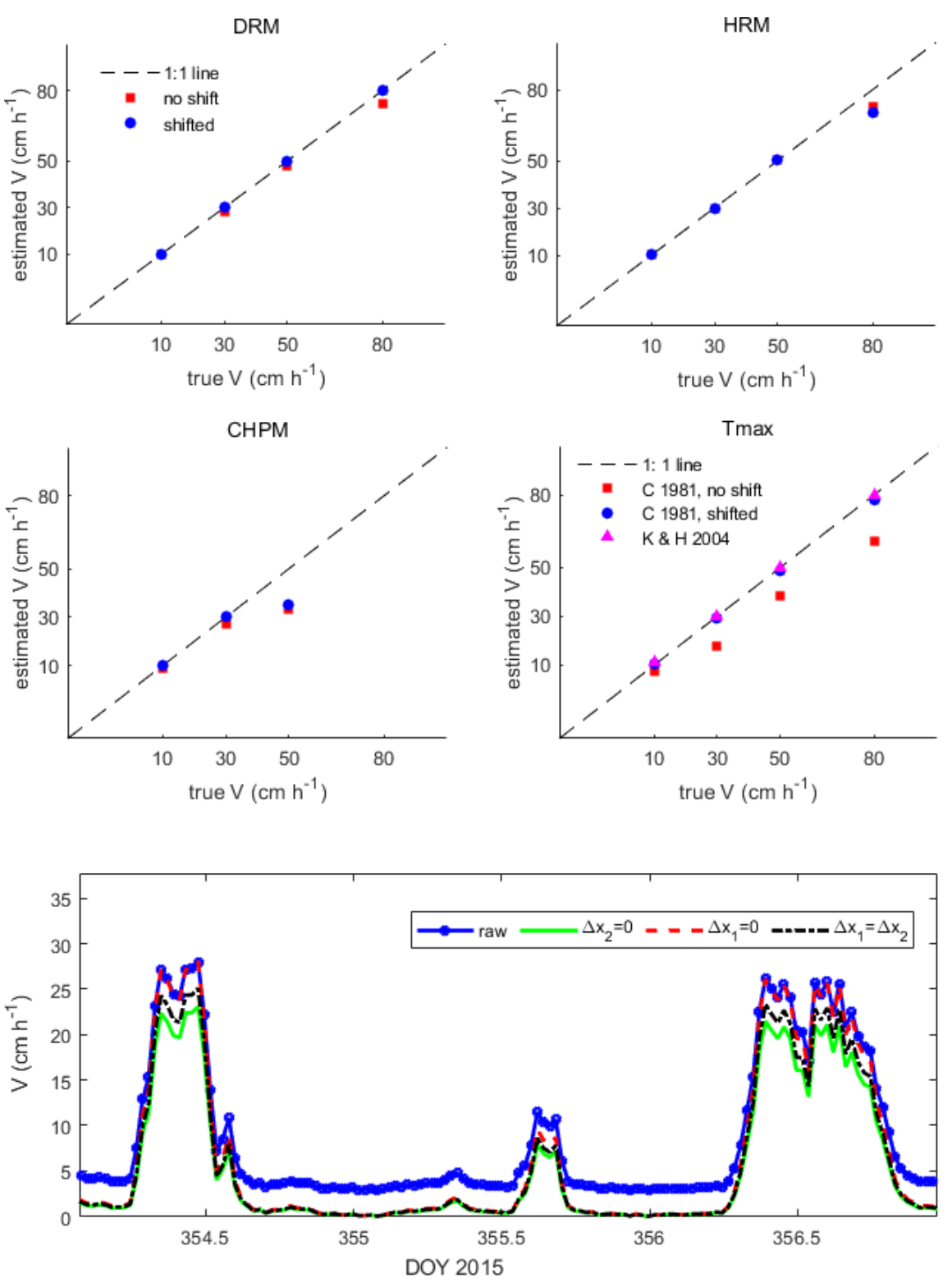

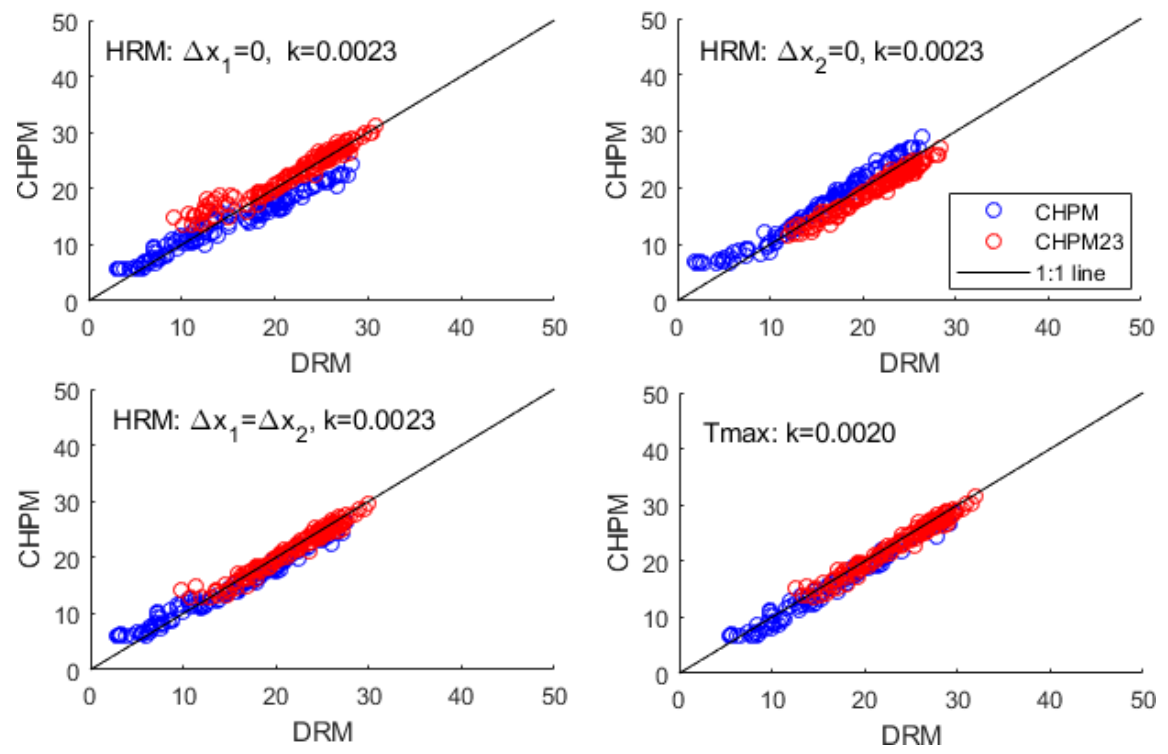